\title{
Topical and Oral Cyclosporine for a Case of Severe Limbal Vernal Keratoconjunctivitis with Complete Corneal Involvement
}

\author{
Norah Fahad Al-Kheraiji ${ }^{1}$ and Hamad Al-Fraikh ${ }^{2}$ \\ ${ }^{1}$ Department of Ophthalmology, King Saud University, Riyadh, Saudi Arabia. \\ ${ }^{2}$ Anterior Segment and Uveitis Divisions, King Khaled Eye Specialist Hospital, Riyadh, Saudi Arabia. \\ http://dx.doi.org/10.13005/bbra/2088
}

(Received: 10 March 2016; accepted: 01 April 2016)

\begin{abstract}
This case report describes the clinical course and management of a patient with severe limbal vernal keratoconjunctivitis, with corneal involvement. The patient had a significant risk of visual loss at presentation. The disease was recalcitrant to conventional treatment. Topical and oral cyclosporine was introduced, resulting in a significant decrease in inflammation. In cases of severe ocular allergic keratoconjunctivitis that is vision threatening and refractory to conventional therapy, oral cyclosporine is a helpful option to to preserve vision and the eye.
\end{abstract}

Key words: Cyclosporine, vernal keratoconjunctivitis, refractory.

\section{Case report}

A 24-year-old male was referred to King Khaled Eye Specialist Hospital (KKESH) for severe uncontrolled vernal keratoconjunctivitis in January 2000. He had been complaining of itching, foreign body sensation, mucoid discharge, tearing and gradual deterioration of vision for the previous eight years. Many of his first-degree relatives had some type of ocular or systemic allergy including his brother. At presentation, he was using cromolyn sodium $4 \%$ qid. His corrected visual acuity was 20/40 OD and 2/200 OS. Spectacle prescription was $-1.5+2.5 \times 114^{\circ} \mathrm{OD}$ and plano OS. There was severe photophobia during exam. Intraocular pressure with Goldmann applanation tonometry was $12 \mathrm{mmHg}$ OU. The conjunctiva was severely congested with thick giant cobblestonelike palpebral papillae. Limbal changes were significant for Horner-Trantas dots, a $360^{\circ}$ corneal

\footnotetext{
* To whom all correspondence should be addressed. E-mail: kheraiji@yahoo.com
}

pannus and opacification worse in the left eye. Topical carboxymethylcellulose four times daily, cromolyn sodium 4\% qid, levocabastine hydrochloride $0.05 \%$ qid and cyclosporine $1 \%$ qid were initiated. Short courses of topical pred forte 1 $\%$ were also prescribed when the disease flared.

On November 2001 the patient had been treated for a shield ulcer in the right eye. Treatment involved ulcer base debridement, soft contact lens placement, ofloxacin drops qid ,fluorometholone $0.1 \%$ qid tapered over 4 weeks, livostin drops and preservative free lubricants. The right eye responded well to treatment and healed without sequelae.

The patient presented in May 2003 with a severe attack of allergic conjunctivitis with limbal hyperplasia covering the cornea completely bilaterally (Fig.1). Vision had dropped to 20/200 OD and counting fingers at four feet OS. A series of blood investigations, purified protein derivative skin test, and chest $\mathrm{X}$-ray were ordered. The patient was cleared medically. Prednisolone $50 \mathrm{mg}$ once daily and cyclosporine $75 \mathrm{mg}$ bid were started. He responded very well both subjectively and 
objectively. Topical cyclosporine 1\% qid was maintained, and the patient was prescribed ophthalmic olopatadine bid and topical carboxymethylcellulose.

Prednisolone was tapered to $2.5 \mathrm{mg}$ daily and cyclosporine reduced gradually and maintained on $25 \mathrm{mg}$ once daily and discontinued in October 2011. Corrected distance visual acuity was 20/40 OU and remained stable throughout the inactive period, and there were no exacerbations since the patient began oral medication until discontinuation.
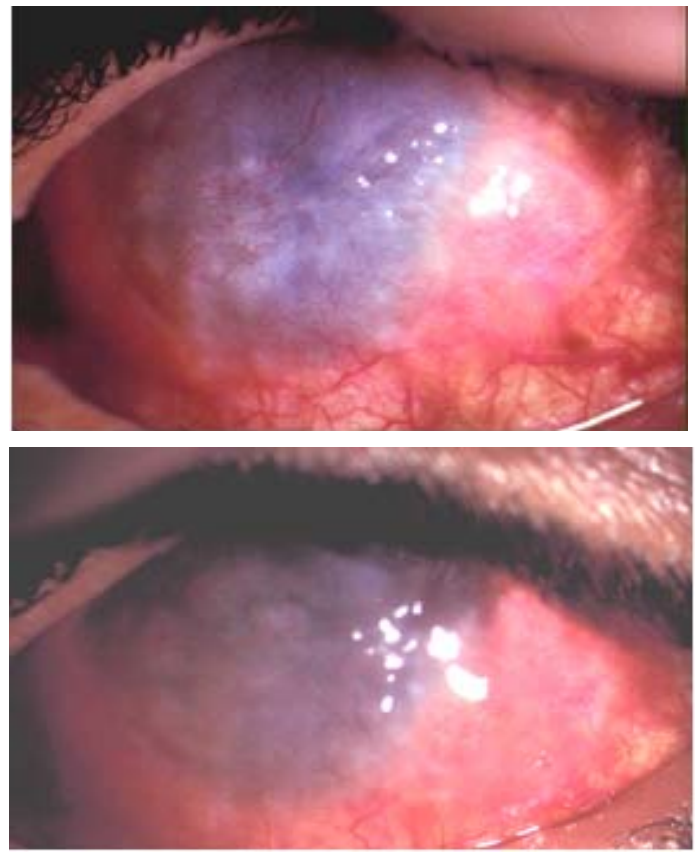

Fig. 1. Severe allergic conjunctivitis with sever limbal hyperplasia invading the cornea and causing sever visual compromise

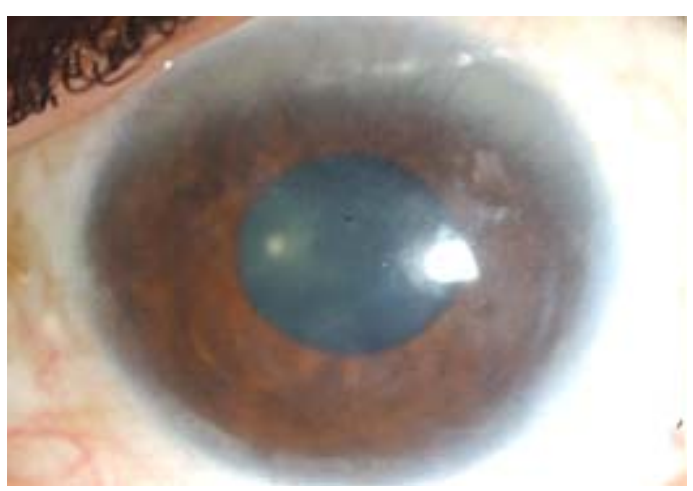

Fig. 2. Quite eye with acceptable central corneal clarity
Corneal topography and refraction indicated keratoconus with satisfactory vision with spectacles. Topical cyclosporine $1 \%$ qid daily and lubricants are being maintained. The patient has two sons, both whom are affected with vernal keratoconjunctivitis, but have milder forms of the disease and are well controlled with topical therapy.

\section{DISCUSSION}

Vernal keratoconjunctivitis (VKC) is a form of allergic conjunctivitis that is more common in males. The male-to-female ratio is 3.2:1 in those younger than 20 years of age, but is equal in older patients ${ }^{1}$. Onset is usually before ten years of age, with the youngest reported at five months of age ${ }^{2}$. At the onset of puberty, the disease becomes less severe. The disease is more common in some regions of the world such as dry, warm subtropical areas. These regions include the Mediterranean region, the Middle East, west and central Africa, South America, Japan, Thailand, India, and some other Asian countries ${ }^{3}$. The name "vernal" was used because exacerbations are seasonal. The pattern usually changes from seasonal attacks to perennial attacks after 3-5 years.

The pathologic of vernal keratoconjunctivitis (VKC) are not entirely understood. Immunoglobulin E (IgE)-mediated hypersensitivity and T helper cell type 2 (Th2)mediated responses are thought to play a major role in VKC ${ }^{4-6}$. Immunoglobulin G (IgG)-mediated responses, basophil hypersensitivity, and cellular delayed-typed hypersensitivity are also believed to play a role.

Development of IgE-mediated reactions is dependent on mast cells that play an important role. Mast cells release mediators that stimulate fibroblast activity and increase the production of collagens I and III, explaining the formation of giant papillae in $\mathrm{VKC}^{7}$. Histamine, interleukins, as well as other inflammatory mediators are found in elevated levels in the tears of VKC patients. The expression of histamine receptors ( $\mathrm{H} 1, \mathrm{H} 2$, and $\mathrm{H} 4$ receptors) is also increased in the conjunctival tissue $^{8-11}$.

Conjunctival levels of Th2 CD4+ cells may give rise to hypereactivity against allergens. Allergens include molds, pollens, wind, heat, animal epithelium, sunlight, dust mites and animal 
epithelium ${ }^{12-14}$.

Management of VKC includes pharmacologic and non-pharmacologic measures. Non-pharmacologic measures include avoiding triggers and allergens. Topical antihistamines and mast cell stabilizers together or alone are usually recommended as first-line therapy and daily usage is recommended throughout the active season. The use of two agents were more effective than mast cell stabilizers or topical antihistamines alone $e^{15-17}$.

Topical corticosteroids are typically the next line of therapy. Corticosteroids also suppress the late-phase of inflammation. A short course, high-dose pulse therapy of topical corticosteroids is often necessary for patients with VKC, who fail to respond to first-line medication.

Calcineurin inhibitors are used in severe cases of ocular allergy, they include topical cyclosporine and tacrolimus and systemic cyclosporine ${ }^{(18)}$. Our patient had a refractory disease and did not respond to conventional therapy. Hence, a systemic immune-modulatory agent to control inflammation was warranted. Cyclosporine-A controls ocular inflammation by blocking the proliferation of Th2 lymphocyte and interleukin 2 (IL) production. It also blocks histamine release from mast cells and basophils and, through reducing IL-5 production. It is also believed that it may reduce the recruitment and the effects of eosinophils on the conjunctiva. Cyclosporine-A reduces the rate of conjunctival fibroblast proliferation and IL-1â production ${ }^{(19)}$. The efficacy of ophthalmic cyclosporine A (0.05$2 \%$ ) for VKC has been well documented with an added steroid-sparing effect ${ }^{(20)}$. In a randomized trial, topical cyclosporine A $0.05 \%$ was more effective than topical ketotifen fumarate $0.025 \%$ in preventing seasonal flare-ups in patients with inactive disease at the start of therapy ${ }^{(21)}$. In summary, severe VKC that is recalcitrant to conventional treatment can be successully treated with cyclosporine to mitigate vision loss and other sequelae.

\section{REFERENCES}

1. Bonini S, Bonini S, Lambiase A, et al. Vernal keratoconjunctivitis revisited: a case series of 195 patients with long-term followup. Ophthalmology 2000; 107:1157.
2. Ukponmwan CU. Vernal keratoconjunctivitis in Nigerians: 109 consecutive cases. Trop Doct 2003; 33:242.

3. Kumar S. Vernal keratoconjunctivitis: a major review. Acta Ophthalmol 2009; 87:133.

4. Leonardi A. Vernal keratoconjunctivitis: pathogenesis and treatment. Prog Retin Eye Res 2002; 21:319.

5. Mantelli F, Lambiase A, Bonini S. A simple and rapid diagnostic algorithm for the detection of ocular allergic diseases. Curr Opin Allergy Clin Immunol 2009; 9:471.

6. Offiah I, Calder VL. Immune mechanisms in allergic eye diseases: what is new? Curr Opin Allergy Clin Immunol 2009; 9: 477.

7. Leonardi A, Abatangelo G, Cortivo R, Secchi AG. Collagen types I and III in giant papillae of vernal keratoconjunctivitis. $\mathrm{Br} \mathrm{J}$ Ophthalmol 1995; 79:482.

8. Abelson MB, Baird RS, Allansmith MR. Tear histamine levels in vernal conjunctivitis and other ocular inflammations. Ophthalmology 1980; 87:812.

9. Leonardi A, Fregona IA, Plebani M, et al. Th1and Th2-type cytokines in chronic ocular allergy. Graefes Arch Clin Exp Ophthalmol 2006; 244: 1240.

10. Leonardi A, Curnow SJ, Zhan H, Calder VL. Multiple cytokines in human tear specimens in seasonal and chronic allergic eye disease and in conjunctival fibroblast cultures. Clin Exp Allergy 2006; 36:777.

11. Leonardi A, Di Stefano A, Vicari C, et al. Histamine $\mathrm{H} 4$ receptors in normal conjunctiva and in vernal keratoconjunctivitis. Allergy 2011; 66: 1360 .

12. Mumcuoglu YK, Zavaro A, Samra Z, Lazarowitz Z. House dust mites and vernal keratoconjunctivitis. Ophthalmologica 1988; 196:175.

13. Fujishima H, Saito I, Takeuchi T, Tsubota K. Immunological characteristics of patients with vernal keratoconjunctivitis. Jpn J Ophthalmol 2002; 46:244.

14. Bonini S, Bonini S, Schiavone M, et al. Conjunctival hyperresponsiveness to ocular histamine challenge in patients with vernal conjunctivitis. J Allergy Clin Immunol 1992; 89:103.

15. Abelson MB. Evaluation of olopatadine, a new ophthalmic antiallergic agent with dual activity, using the conjunctival allergen challenge model. Ann Allergy Asthma Immunol 1998; 81:211.

16. Abelson MB, Spitalny L. Combined analysis of two studies using the conjunctival allergen challenge model to evaluate olopatadine 
hydrochloride, a new ophthalmic antiallergic agent with dual activity. Am J Ophthalmol 1998; 125:797.

17. Berdy GJ, Stoppel JO, Epstein AB. Comparison of the clinical efficacy and tolerability of olopatadine hydrochloride $0.1 \%$ ophthalmic solution and loteprednol etabonate $0.2 \%$ ophthalmic suspension in the conjunctival allergen challenge model. Clin Ther 2002; 24:918.

18. Miyazaki D, Tominaga T, Kakimaru-Hasegawa A, et al. Therapeutic effects of tacrolimus ointment for refractory ocular surface inflammatory diseases. Ophthalmology 2008; 115: 988.
19. Leonardi A. Emerging drugs for ocular allergy. Expert Opin Emerg Drugs. 2005;10:505-20.

20. Tesse R, Spadavecchia L, Fanelli P, Rizzo G, Procoli U, Brunetti L, et al. Treatment of severe vernal keratoconjunctivitis with $1 \%$ topical cyclosporine in an Italian cohort of 197 children. Pediatr Allergy Immunol. 2010;21:330-5.

21. Lambiase A, Leonardi A, Sacchetti M, et al. Topical cyclosporine prevents seasonal recurrences of vernal keratoconjunctivitis in a randomized, double-masked, controlled 2-year study. J Allergy Clin Immunol 2011; 128: 896. 